\title{
Are There Biological Bases for a Beneficial Effect of Estrogens in Neural Diseases?
}

\author{
A. Maggi, P. Ciana, A. Brusadelli, S. Belcredito, C. Bonincontro, \\ and $\mathrm{E}$. Vegeto \\ Center Milan Molecular Pharmacology Lab, Institute of Pharmacological Sciences, \\ University of Milan, Milan, 20133 Italy
}

Received August 9, 2000; accepted May 1, 2001

Recent epidemiological studies showing that estrogen administration in postmenopausal women has beneficial effects by delaying the manifestation of neurodegenerative diseases of few years has raised a lot of justified interest (Stampfer and Colditz, 1991; Henderson, Paganini-Hill, Emanuel, Dunn, and Buckwalter, 1994; Paganini-Hill and Henderson, 1994). However, this excitement has been tempered by ensuing investigations that did not always confirm the original findings (Mulnard, 2000). At the present time, the issue of a neuroprotective effect of estrogens is still quite controversial. Results of the specially designed ongoing clinical trials will hopefully clarify the controversial issues. At the current time, one could evaluate the biological reasons for the reported beneficial effects of estrogens on neurodegenerative diseases during aging based on their known physiological functions.

The purpose of this paper is to provide a brief review of the present knowledge of the mechanisms of estrogen action in the different neural cells targeted by the hormone, mainly based on results obtained in our laboratory.

\section{CELL TARGETS FOR ESTROGEN ACTION IN THE CENTRAL NERVOUS SYSTEM}

Estrogen receptors (ERs) were found in all the cells present in the central nervous system. Besides neurons, which have long been known to express the ERs (originally the $\alpha$ form and then the $\beta$ ) (Couse, Lindzey, Grandien, and Gustafsson, 1997), the presence of ERs has also been found in glial cells (Jung-Testas, Renoir, Bugnard, Greene, and Baulieu, 1992; Santagati, Melcangi, Celotti, Martini, and Maggi, 1994). Very recently, our laboratory has shown that microglia is a target for estrogen (Vegeto, Bonincontro, Pollio, Sala, Viappiani, Nardi, Puglisi, Ciana, and Maggi, 2000) and that stem cells in adult rat also express the ERs (Pollio, in preparation). Because all of the neural cell systems are interconnected, the final effect of the estrogens reaching the brain will result from the sum of specific actions in different brain regions and cell types.

\section{ESTROGEN ACTIVITY IN NEURONS}

\section{E 2 Controls the Differentiation of Stem Cells and Affects the Morphology of Mature Neurons}

It is well known that in the neonatal brain of male rodents estrogens play an essential role in the differentiation of the hypothalamic-pituitary-gonadal axis (Baum, 1979; Cherry, Tobet, DeVoogt, and Baum, 1992; McCarthy, 1994). This effect ensures that the adult brain will be able to activate masculine behavior in response to aromatized androgens. A large number of behavioral and biochemical studies support this theory, and $\mathrm{ER} \alpha \mathrm{KO}$ male mice fail to display correct masculine behavior (Wersinger, Sannen, Villalba, Lubahn, Rissman, and De Vries, 1997). Less well studied are the developmental effects of estrogens in brain areas other than reproductive ones. However, in the adult mammalian brain, there are several sexual dimorphic regions: one example is the hippocampal structure. The dentate of males has a greater total number of granulosa cells and the hilus more mossy fiber synapses than those of females (Madeira and Paula-Barbosa, 1993). These structural differences may explain the sexual dimorphism in the performance of various hippocampal-dependent tasks (Daniel, Fader, Spencer, and Dohanich, 1997; Packard and Teather, 1997; Luine, Richards, Wu, and Beck, 1998).

Estrogens also play an important role in the devel- 
oping female brain. In spite of the fact that sex-related neural circuits are feminine by default, estrogen or better estrogen receptors may still have some role in the differentiation of female-specific patterns. Certainly in the adult brain estrogens strongly influence the plasticity of neurons located in different part of the brain (Wolley and McEwen, 1992; Daniels, 2000).

Thus estrogens may act as differentiating agents in neuroblasts. It is no surprise therefore that Tanapat, Hastings, Reeves, and Gould (1999) found that estrogens induce the differentiation of precursors of neurons in the hippocampus of adult female rats, eventually leading to sex-specific behaviors or learning capabilities (Gould, Tanapat, Hastings, and Short, 1999).

In still unpublished data, we showed that, in adult mouse, brain stem cells both express ERs and respond to estrogens with proliferation. The analysis of the effect of estrogens in stem cells in vitro will open new horizons on the mechanisms underlying hormone effects during the maturation of the nervous system. Interestingly, experiments carried out in our laboratory indicate that estradiol may unfold its differentiative potential even in neuroblastoma cells. In our studies, we used a neuroblastoma cell line believed to represent a very early stage of the differentiation process leading to a mature neuron of the peripheral nervous system (PNS) (Ma, Spreafico, Pollio, Santagati, Conti, Cattaneo, and Maggi, 1993; Agrati, Ma, Patrone, Picotti, Pellicciari, Bondiolotti, Bottone, and Maggi, 1997). This cell line was stably transfected with $\mathrm{ER} \alpha$. Interestingly, when the ER $\alpha$-transfected neuroblastoma cells were treated with the hormone, they ceased growth and differentiated toward a well-defined phenotype. During this process, the hormone induced the synthesis of a number of proteins already known to be modulated by estrogens in neural cells, such as synaptophysins (Arai and Matsumoto, 1978; Ma et al., 1993), Tau (Uchibori and Kawashimi, 1985; Ferreira and Caceres, 1991), calbindin, and tyrosine hydroxylase (Kohama and Bethea, 1995; Raab, Pilgrim and Reisert, 1995; Agrati et al., 1997). These finding strongly support the hypothesis of very reproducible activity of estrogens in target cells of the same type.

\section{Estrogen Influences the Survival of Neurons in the Presence of Neurotoxic Agents}

Recently, several studies demonstrated an anti-apoptotic effect of $17 \beta$-estradiol (E2) in a number of cell systems (Billig, Furuta, and Hsueh, 1993; Spyridopoulos, Sullivan, Kearney, Isner, and Losordo, 1997; Veg- eto, Pollio, and Maggi, 1999), including neural cells (Behl, Widmann, Trapp, and Holsboer, 1995; Goodman, Bruce, Cheng, and Mattson, 1996; Green, Gridley, and Simpkins, 1996; McMillian, Singer, and Dorsa, 1996; Toran-Allerand, 1996; Behl, Skutella, Lezoualc'h, Post, Widmann, Newton, and Hoslboer, 1997; Hashimoto, Inoue, Maramatsu, and Masliah, 1997; GarciaSegura, Cardona-Gomez, Naftolin, and Chowen, 1998; $\mathrm{Xu}$, Gouras, Greenfieeld, Vincent, Naslund, Mazzarelli, Fried, Jovanovic, Seeger, Relkin, Liao, Checler, Buxbaum, Thinakaran, Sisodia, Wang, Greengard, and Gandy, 1998; Pike, 1999). The neuroprotective action has been claimed to be independent of genomic, receptor-mediated activity. Behl's and other groups showed that in immortalized hippocampal cells not expressing the ER, or in dissociated embryo neurons, E2 protects from glutamate excitotoxicity, oxidative stress, or $\beta$-amyloid at a concentration of $100 \mathrm{nM}-10$ $\mu \mathrm{M}$ (Behl et al., 1995; Goodman et al., 1996; Regan and Guo, 1997). This observation led us to propose that estrogens may act as antioxidants (Behl et al., 1995, 1997; Goodman et al., 1996; Green et al., 1996; GarciaSegura et al., 1998; Xu et al., 1998). Several authors have suggested that the protective effect of E2 is exerted via modulation of cytoplasmic transduction signals induced via nongenomic paths (Hashimoto et al., 1997). Others favor a genomic effect which results in the decreased synthesis of glutamate receptors, augmented expression of neurotrophic factors (McMillian et al., 1996; Toran-Allerand, 1996), or antiapoptotic proteins (Garcia-Segura et al., 1998; Pike, 1999). The existence of a protective effect of E2 in cells not expressing ER, together with the finding that E2 at a high concentration exerts antioxidant effects, may indeed explain the antiapoptotic activity of E2 in a number of cell systems. However, other studies showed a lack of protection by low concentrations of E2 in cells of neural origin deprived of ER (SK-N-BE) and a protection in the same cells stably transfected with ER $\alpha$. This clearly indicates the involvement of genomic effects in E2-dependent protection (Meda, Vegeto, Pollio, Ciana, Patrone, Pellicciari, and Maggi, 2000).

The interpretation of protective effects of estrogens via a genomic mechanism is also supported by the observation that estradiol regulates the expression of several genes implicated in the apoptotic process. In particular, E2 was described as increasing the synthesis of Bcl 2 in MCF-7 cells (Teixeira, Reed, and Pratt, 1995) and decreasing the expression of a novel proapoptotic gene, nip2, in neuroblastoma (Garnier, Di Lorenzo, Albertini, and Maggi, 1997) and in rat embryo neurons in primary culture (Meda, Vegeto, Pol- 
lio, Ciana, Patrone, Pellicciari, and Maggi, 2000). These observations led us to hypothesize that estrogens may contribute to maintain the equilibrium between proand antiapoptotic molecules within neural cells, thus buffering the activity of neurotoxic compounds that offset the balance among these factors and trigger the apoptotic cascade (Meda et al., 2000).

\section{Estrogen and Neurotransmission}

Several classical studies have shown a correlation between increased circulating levels of estradiol and augmented neuronal firing activity. More recently, it has been shown that estrogens increase neuronal metabolic activities by increasing the mitochondrial functions and inducing the synthesis of enzymes of the respiratory chain (e.g., cytochrome C oxidase) (Van Itallie and Dannies, 1988; Bettini and Maggi, 1992). Estrogens possibly increase the synaptic activity of neurons by facilitating the de novo synthesis of neurotransmitters via transcription of genes coding key enzymes like tyrosine hydroxylase (Kohama and Bethea, 1995; Raab et al., 1995; Agrati et al., 1997) and choline acetyl transferase (McMillian et al., 1996) in the synthetic pathway of dopamine and acetylcholine. Finally, it is likely that estrogens facilitate the intracellular trafficking of important metabolites/ neurotransmitters by controlling the synthesis and assembly of microtubules (e.g., tau) (Uchibori and Kawashimi, 1985; Ferreira and Caceres, 1991) and providing the proteins necessary for the assembly of storage compartments like secretory vesicles and granules (e.g., synaptophysin) (Arai and Matsumoto, 1978; Ma et al., 1993).

\section{ESTROGEN ACTIVITY IN GLIA}

Brain development and activity depend on coordinated functional interactions between glia and neurons. Electrophysiological and biochemical studies have shown that synaptically released neurotransmitters may activate receptors in glia to affect their membrane potential (Dani, Chernjavsky, and Smith, 1992; Duffy and MacVicar, 1995; Verkhratsky and Kettenmann, 1996; Chen, Backus, and Deitmer, 1997; Pasti, Voltera, Pozzan, and Carmignoto, 1997). In turn, glia remove neurotransmitters from the extracellular space and maintain proper ionic balance. Moreover, glutamate released from glia has been shown to modulate evoked and spontaneous synaptic transmission in neurons (Araque, Sanzgiri, Parpura, and Haydon,
1998). Together, these bidirectional interactions mediate neuronal-glial communication and indicate that glia play an active role in influencing neuronal activity.

Recent evidence demonstrates that glial cells (oligodendrocytes and astrocytes) may be a target of gonadal steroids since they express both $\operatorname{ER} \alpha$ and $\beta$ (Joung-Testas et al., 1992; Santagati et al., 1994; Buchanan, Mahesh, and Brann, 2000). Furthermore, a series of very interesting studies suggest that astroglial cells targeted by gonadal steroids are actively involved in organizational and activational effects of estrogens in particular. Sex hormones have been reported to perform various functions.

\section{Hormones Promote Astroglial Differentiation and Plasticity}

The focus of most studies on the effects of gonadal steroids on glia relates to investigations on astroglial activity in the rodent hypothalamus. Sex differences in the morphology of astroglia and on the expression of astroglial markers have been widely reported for several hypothalamic regions (Tobet and Fox, 1989; Suarez, Bodega, Rubio, and Fernandez, 1991; Chowen, Busiguina, and Garcia-Segura, 1995; Garcia-Segura, Duenas, Busiguina, Naftolin, and Chowen, 1995; Mong, Kurzweil, Davis, Rocca, and McCarthy, 1996). Changes in GFAP have been described during the estrous cycle in the arcuate nucleus (Garcia-Segura, Chowen, Parducz, and Naftolin, 1994b; Garcia-Segura, Luquin, Parducz, and Naftolin, 1994a), but also in the hilus of the dentate gyrus (Luquin, Naftolin, and Garcia-Segura, 1993). In addition, several studies have shown that estradiol promotes astroglial differentiation and growth in vitro (Del Cerro, Garcia-Estrada, and Garcia-Segura, 1995).

\section{Hormones Affect Glial Plasticity to Regulate the Generation of a Sexually Dimorphic Pattern of Neuronal Synaptic Contacts}

Recent studies suggest that astroglia may be involved in the organizational effects of sex steroids in the arcuate neurons. It has been in fact proposed that testosterone converted to estradiol regulates the generation of the sexually dimorphic pattern of synaptic contacts by affecting the growth of astroglial processes on neuronal surfaces, thus controlling and limiting the amount of membrane available for the establishment of synaptic contacts (Garcia-Segura et al., 1995). 


\section{Hormones Modulate Astroglial Secretory Activity}

Several reports have shown that E2 may control the expression of genes for growth factors. It is conceivable that this hormone controls the synthesis and release of neurotrophin by glia. Recent reports support this hypothesis by showing that in astroglia in culture, $17 \beta$ - but not $17 \alpha$-estradiol induces an increase in the expression of TGF $\alpha$ and TGF $\beta$ expression (Buchanan et al., 2000). This effect is interesting because this growth factor is involved in the regulation of luteinizing hormone-releasing hormone (LHRh) secretion from hypothalamic structures (Ma, Junier, Costa, and Ojeda, 1992). Ojeda et al. suggested that TGF $\alpha$ regulates LHRh release via a glial to neuron signaling pathway acting on prostaglandin E2 receptors in LHRh neurons (Rage, Lee, Ma, and Ojeda, 1997). Changes in astrocytic functions may also underlie the neurochemical and morphological alterations in limbic and cortical areas. For instance, results from the Stewart laboratory have shown that the immunoreactivity to bFGF in the ventral tegmental area was greater in ovariectomized rats than in intact or E2treated females (Flores, Salmaso, Cain, Rodaros, and Stewart, 1999). Since bFGF secretion is generally indicative of the astrocytic response to neuronal injury, it is postulated that at least some of the secretory activities observed following changes in E2 levels are triggered by altered neuronal metabolism.

\section{ESTROGEN ACTIVITY IN MICROGLIA}

Microglia are the resident macrophages of the brain. After neuronal injury and in several neurodegenerative diseases, activated microglia secrete proinflammatory molecules that can contribute to progressive neural damage. Ramified resting microglia once activated acquire a well-described ameboid morphology distinctive of the change in their physiological activities. Recent studies carried out in our laboratory (Vegeto et al., 2000) show that E2 treatment of resting microglia prior to its activation with lipopolysaccharide or other inflammatory stimuli, prevents the morphological differentiation associated with activation. In addition, we showed that estrogen treatment prevents the secretion of several inflammatory stimuli, such as metalloproteases (metalloproteinase-9 or MMP-9) and prostaglandins ( $\left.\mathrm{PGE}_{2}\right)$, and blocks the LPS-induced increase of iNOS synthesis and activity (Vegeto et al., 2000). These effects seem to be mediated by the ERs because they are blocked by specific ER antagonists. Furthermore, immunocytochemical and RT-PCR studies show the presence of ER $\alpha$ protein and $E R \alpha$ and $E R \beta$ mRNA in primary cultures of 2-day-old rats.

These findings point to a potential anti-inflammatory effect of estrogens in the nervous system. This finding may have important repercussions in the understanding of the beneficial role of estrogens in neurodegenerative diseases.

\section{MECHANISM OF ESTROGEN ACTION IN TARGET CELLS-THE SIGNIFICANCE OF THE IDENTIFICATION OF ESTROGEN TARGET GENES IN NEURAL CELLS}

It is possible that, in molecular terms, the effects of estrogens are very similar in each type of cell in the nervous system. If this were the case, the comprehension of the mechanism of action of the hormone in cells of neural origin might explain the biochemical bases for its beneficial role in neurodegeneration. Estrogens intervene in the functions of the target cells by binding to specific receptors. So far only two intracellular receptors, named estrogen receptor- $\alpha$ and $-\beta$ (ER $\alpha$ and $\mathrm{ER} \beta$ ), have been described (Kuiper, Enmark, Pelto-Huikko, Nilsson, and Gustaffson, 1996). Once in a complex with the hormone, the receptor acquires the capability of recognizing and binding selected sequences in the promoter of specific genes. The hormone-receptor complex bound to DNA interacts with other proteins of the transcriptional apparatus (either general or cell-specific transcription factors) to initiate the process leading to RNA synthesis. Since the estrogen-receptor complex recognizes the same DNA sequences, its activity should be identical in all the target cells. This is not the case and several factors contribute to the cell-specificity of the action of estrogens such as: (a) developmental cues-during the process of cell differentiation, fragments of the genome are enzymatically modified or are bound by specific proteins and become inaccessible to transcription factors. This process will undoubtedly involve some of the ER-inducible promoters that will become insensitive to hormone activity; (b) tissue-specific transcription elements-as mentioned above, the ER must interact with transciption factors to initiate the transcription of target genes. These factors are in part ubiquitous and in part cell-specific. Therefore, the abundance of these cell-specific proteins will affect E2-ER action on indi- 
vidual promoters; (c) receptor dosage-ER can be upor down-regulated; most likely a higher concentration of the receptor protein will allow the hormone to stimulate most of the target promoters, while lower concentrations will allow generation of subgroups of transcripts, e.g., from genes whose promoter possesses multiple EREs; (d) Ligand characteristics-ER may bind E2 and some of its metabolites. This has consequences for the conformation of the bound receptor and therefore for its functional activity; (e) receptor subtype-the type of ER expressed in a single cell might also be important for the selectivity of estrogen action. However, in cells having a common origin the genes transcriptionally affected by the hormone should be alike. It is conceivable, however, that in cells of the same type the effects of the hormone, though qualitatively identical, are quantitatively different, depending on other environmental cues affecting the physiology of the cell. On this basis, we used as a model the neuroblastoma cell line described above to identify genes induced by the hormone. During estrogen-dependent differentiation, we observed the increased synthesis of proteins whose coding genes are a known target for the hormone in neurons such as synaptophysin (Arai and Matsumoto, 1978; Ma et al., 1993), Tau (Uchibori and Kawashimi, 1985; Ferreira and Caceres, 1991), and tyrosine hydroxylase (Kohama and Bethea, 1995; Raab et al., 1995; Agrati et al., 1997). We then used these cells to identify estrogenregulated genes by the ddPCR approach (Garnier et al., 1997). So far all of the genes identified in the neuroblastoma system also appear to be under estrogen control in neurons of the central nervous system (CNS). In particular we studied the genes coding for subunits of the mitochondrial enzyme cytochrome $C$ oxidase, Nip2, and prothymosine- $\alpha$ L7. These results support the view of the similarity of action of estrogens in neurons of both the PNS and the CNS.

\section{CONCLUSIONS}

From above reports it appears that the studies carried out so far permit a very limited insight into the mechanisms and functions which can be regulated by estrogens. The view of a beneficial effect of estrogens in neurodegenerative diseases certainly needs to be pursued and the lines of evidence supporting positive effects of this hormone on CNS functioning are quite strong. Estrogen may ameliorate the performance of experimental animals in behavioral and memory tests because of its acute effects on the release of neuro- transmitters or because of its longstanding effects on neurons, such as increased mitochondrial activity, synthesis and storage of neurotransmitters, regulation of the balance between apoptotic and antiapoptotic factors, increased synthesis of growth factors from glia, and anti-inflammatory activity in microglia. However, as suggested by the most recent clinical studies, the presence of the hormone by itself may not be sufficient to block ongoing pathological processes; conversely its continuous action may contribute to the preservation of the mechanisms relevant for brain well-being.

\section{ACKNOWLEDGMENTS}

The work carried out was supported by grants from the Italian Association for Cancer Research (AIRC); CNR Targeted Project Biotechnologies; Telethon (E600); and Murst 40\%, European Community (BIOMED Programme BMH4-CT97-2286).

\section{REFERENCES}

Agrati, P., Ma, Z. Q., Patrone, C., Picotti, G. B., Pellicciari, C., Bondiolotti, G., Bottone, M. G., and Maggi, A. (1997). Dopaminergic phenotype induced by estrogens in a human neuroblastoma cell line. Eur. J. Neurosci. 9, 1008-1016.

Arai, Y., and Matsumoto, A. (1978). Synapse formation of the hypothalamic arcuate nucleus during post-natal development in the female rat and its modification by neonatal estrogen treatment. Psychoneuroendocrinology 3, 31-45.

Araque, A., Sanzgiri, R. P., Parpura, V., and Haydon, P. G. (1998). Calcium elevation in astrocytes causes an NMDA receptor-dependent increase in the frequency of miniature synaptic currents in cultured hippocampal neurons. J. Neurosci. 18, 6822-6829.

Baum, M. J. (1979). A comparison of the effects of methyltrienolone (R1881) and 5 alpha-dihydrotestosterone on sexual behavior of castrated male rats. Horm. Behav. 2, 165-174.

Behl, C., Skutella, T., Lezoualc'h, F., Post, A., Widmann, M., Newton, C. J., and Holsboer, F. (1997). Neuroprotection against oxidative stress by oestrogens: structure-activity relationship. Mol. Pharmacol. 51, 535-541.

Behl, C., Widmann, M., Trapp, T., and Holsboer, F. (1995). 17- $\beta$ Estradiol protects neurons from oxidative stress-induced cell death in vitro. Biochem. Biophys. Res. Commun. 216, 473-482.

Bettini, E., and Maggi, A. (1992). Estrogen induction of cytochrome C oxidase subunit III in rat hippocampus. J. Neurochem. 58, 19231929.

Billig, H., Furuta, I., and Hsueh, A. J. (1993). Estrogens inhibit and androgens enhance ovarian granulosa cell apoptosis. Endocrinology 133, 2204-2212.

Buchanan, C. D., Mahesh, V. B., and Brann, D. W. (2000). Estrogenastrocyte-luteinizing hormone-releasing hormone signaling: A role for transforming growth factor- $\beta_{1}$. Biol. Reprod. 62, 17101721.

Chen, J., Backus, K. H., and Deitmer, J. W. (1997). Intracellular 
calcium transients and potassium current oscillations evoked by glutamate in cultured rat astrocytes. J. Neurosci. 17, 7278-7287.

Cherry, T. A., Tobet, S. A., DeVoogt, T. J., and Baum, M. J. (1992). Effect of estrogen and androgen treatment on dendritic dimensions of neurons of sexually dimorphic preoptic/anterior hypothalamic area of male and female ferrets. J. Comp. Neurol. 323, 577-585.

Chowen, J. A., Busiguina, S., and Garcia-Segura, L. M. (1995). Sexual dimorphism and sex steroid modulation of glial fibrillary acidic protein messenger RNA and immunoreactive levels in the rat hypothalamus. Neuroscience 69, 519-532.

Couse, J. F., Lindzey, j., Grandien, K., and Gustafsson, J.-A. (1997). Tissue distribution and quantitative analysis of estrogen receptoralpha (ER-alpha) and estrogen receptor-beta (ER-beta) meesenger ribonucleic acid in the wild-type and ER alpha-knock-out mouse. Endocrinology 138, 4613-4621.

Dani, J. W., Chernjavsky, A., and Smith, S. J. (1992). Neuronal activity triggers calcium waves in hippocampal astrocyte networks. Neuron 8, 429-440.

Daniel, J. M., Fader, A. J., Spencer, A. L., and Dohanich, G. P. (1997) Estrogen enhances performance of female rats during acquisition of a radial arm maze. Horm. Behav. 32, 217-225.

Daniels, D., and Flanagan-Cato, L. M. (2000). Functionally-defined compartments of the lordosis neural circuit in the ventromedial hypothalamus in female rats. J. Neurobiol. 45, 1-13.

Del Cerro, S., Garcia-Estrada, J., and Garcia-Segura, L. M. (1995). Neuroactive steroids regulate astroglia morphology in hippocampal cultures from adult rats. Glia 14, 65-71.

Duffy, S., and MacVicar, B. A. (1995). Adrenergic calcium signaling in astrocyte networks within the hippocampal slice. J. Neurosci. 15, 5535-5550.

Ferreira, A., and Caceres, A. (1991). Estrogen-enhanced neurite growth. Evidence for a selective induction of tau and stable microtubules. J. Neurosci. 11, 392-400.

Flores, C., Salmaso, N., Cain, S., Rodaros, D., and Stewart, J. (1999). Ovariectomy of adult rats leads to increased expression of astrocytic basic fibroblast growth factor in the ventral tegmental area and in dopaminergic projection regions of the entorhinal and prefrontal cortex. J. Neurosci. 19, 8665-8673.

Garcia-Segura, L. M., Luquin, S., Parducz, A., and Naftolin, F. (1994a). Gonadal hormone regulation of the glial fibrillary acidic protein immunoreactivity and glial ultrastructure in the rat neuroendocrine hypothalamus. Glia 10, 59-69.

Garcia-Segura, L. M., Chowen, J. A., Parducz, A., and Naftolin, F. (1994b). Gonadal hormones as promoters of structural synaptic plasticity: Cellular mechanisms. Prog. Neurobiol. 44, 279-307.

Garcia-Segura, L. M., Duenas, M., Busiguina, S., Naftolin, F., and Chowen, J. A. (1995). Gonadal hormone regulation of neuronalglia interactions in the developing neuroendocrine hypothalamus. J. Steroid Biochem. Mol. Biol. 53, 293-298.

Garcia-Segura, L. M., Cardona-Gomez, P., Naftolin, F., and Chowen, J. A. (1998). Estrogen upregulates Bcl-2 expression in adult brain neurons. Neuroreport 9, 593-597.

Garnier, M., Di Lorenzo, D., Albertini, A., and Maggi, A. (1997). Identification of oestrogen-responsive genes in neuroblastoma SK-ER3 cells. J. Neurosci. 17, 4591-4599.

Goodman, Y., Bruce, A. J., Cheng, B., and Mattson, M. P. (1996). Oestrogens attenuate and corticosterone exacerbates excitotoxicity, oxidative injury and amyloid $\beta$-peptide toxicity in hippocampal neurons. J. Neurochem. 66, 1836-1844.

Gould, E., Tanapat, P., Hastings, N. B., and Short, T. J. (1999).
Neuritogenesis in adulthood: A possible role in learning. Trends Cogn. Sci. 3, 186-192.

Green, P. S., Gridley, K. E., and Simpkins, J. W. (1996). Estradiol protects against beta-amyloid (25-35)-induced toxicity in SKN-SH human neuroblastoma cells. Neurosci. Lett. 218, 165-168.

Hashimoto, M., Inoue, S., Muramatsu, M., and Masliah, E. (1997). Estrogens stimulates tamoxifen-induced neuronal cell apoptosis in vitro: A possible non-genomic action. Biochem. Biophys. Res. Commun. 240, 464-470.

Henderson, V. W., Paganini-Hill, A., Emanuel, C. K., Dunn, M. E., and Buckwalter, J. G. (1994). Estrogen replacement therapy in older women. Comparisons between Alzheimer's disease cases and nondemented control subjects. Arch. Neurol. 51, 896-900.

Jung-Testas, I., Renoir, M., Bugnard, H., Greene, G. L., and Baulieu, E. E. (1992). Demonstration of steroid hormone receptors and steroid action in primary cultures of rat glial cells. J. Steroid Biochem. Mol. Biol. 41, 621-631.

Kohama, S. G., and Bethea, C. L. (1995). Steroid regulation of tyrosine hydroxylase messenger ribonucleic acid in dopaminergic subpopulation of monkey hypothalamus. Endocrinology 136, 1790-1800.

Kuiper, G. G. J. M., Enmark, E., Pelto-Huikko, M., Nilsson, S., and Gustafsson, J.-A. (1996). Cloning of a novel receptor expressed in rat prostate and ovary: Proc. Natl. Acad. Sci. USA 93, 5925-5930.

Luine, V. N., Richards, S. T., Wu, V. Y., and Beck, K. D. (1998). Estradiol enhances learning and memory in a spatial memory task and effects levels of monoaminergic neurotransmitters. Horm. Behav. 34, 149-162.

Luquin, S., Naftolin, F., and Garcia-Segura, L. M. (1993). Natural fluctuation and gonadal hormone regulation of astrocyte immunoreactivity in dentate gyrus. J. Neurobiol. 24, 913-924.

Ma, Y. J., Junier, M. P., Costa, M. E., and Ojeda, S. R. (1992). Transforming growth factor-alpha gene expression in the hypothalamus is developmentally regulated and linked to sexual maturation. Neuroreport 9, 657-670.

Ma, Z. Q., Spreafico, E., Pollio, G., Santagati, S., Conti, E., Cattaneo, E., and Maggi, A. (1993). Activated estrogen receptor mediates growth arrest and differentiation of a neuroblastoma cell line. Proc. Natl. Acad. Sci. USA 90, 3740-3744.

Madeira, M. D., and Paula-Barbosa, M. M. (1993). Reorganization of mossy fiber synapses in male and female hypothyroid rats: A stereological study. J. Comp. Neurol. 337, 334-352.

McCarthy, M. M. (1994). Molecular aspects of sexual differentiation of the rodent brain. Psyconeuroendocrinology 19, 415-427.

McMillian, P. J., Singer, C. A., and Dorsa, D. M. (1996). The effects of ovariectomy and estrogen replacement on trkA and choline acetyltransferase mRNA expression in the basal forebrain of the adult female Sprague-Dawley rat. J. Neurosci. 16, 1860-1865.

Meda, C., Vegeto, E., Pollio, G., Ciana, P., Patrone, C., Pellicciari, C., and Maggi, A. (2000). Oestrogen prevention of neural cell death correlates with decreased expression of mRNA for the pro-apoptotic protein Nip-2. J. Neuroendocrinol. 12, 1-10.

Mong, J. A., Kurzweil, R. L., Davis, A. M., Rocca, M. S., and McCarthy, M. M. (1996). Evidence for sexual differentiation of glia in rat brain. Horm. Behav. 30, 553-562.

Mulnard, R. A. (2000) Estrogen as a treatment for Alzheimer's disease. J. Am. Med. Assoc. 284, 307-308.

Packard, M. G., and Teather, L. (1997). Intra-hippocampal estradiol infusion enhances memory in ovariectomized rats. Neuroreport $\mathbf{8}$, 3009-3013.

Paganini-Hill, A., and Henderson, V. W. (1994). Estrogen deficiency 
and risk of Alzheimer's disease in women. Am. J. Epidemiol. 140, 256-261.

Pasti, L., Volterra, A., Pozzan, T., and Carmignoto, G. (1997). Intracellular calcium oscillations in actrocytes: A highly plastic, bidirectional form of communication between neurons and astrocytes in situ. J. Neurosci. 17, 7817-7830.

Pike, C. J. (1999). Estrogen modulates neuronal Bcl-Xl expression and $\beta$-amyloid-induced apoptosis: Relevance to Alzheimer's disease. J. Neurochem. 72, 1552-1563.

Raab, H., Pilgrim, C., and Reisert, I. (1995). Effect of sex and estrogen on tyrosine hydroxylase mRNA in cultured embryonic rat mesencephalon. Brain Res. 33, 157-164.

Rage, F., Lee, B. J., Ma, Y. J., and Ojeda, S. R. (1997). Estradiol enhances prostaglandin E2 receptor gene expression in luteinizing hormone-releasing hormone (LHRH) neurons and facilitates the LHRH response to PGE2 by activating a glia-to-neuron signaling pathway. J. Neurosci. 17, 9145-9156.

Regan, R. F., and Guo, Y. (1997). Estrogens attenuate neuronal injury due to hemoglobin, chemical hypoxia and excitatory aminoacids in murine cortical cultures. Brain Res. 764, 133-140.

Santagati, S., Melcangi, R. C., Celotti, F., Martini, L., and Maggi, A. (1994). Estrogen receptor is expressed in different types of glial cells in culture. J. Neurochem. 63, 2058-2064.

Spyridopoulos, I., Sullivan, A. B., Kearney, M., Isner, J. M., and Losordo, D. W. (1997). Estrogen-receptor-mediated inhibition of human endotelial cell apoptosis. Circulation 95, 1505-1514.

Stampfer, M. J., and Colditz, G. (1991). Estrogen replacement therapy and coronary heart disease: A quantitative assessement of the epidemiologic evidence. Prev. Med. 20, 47-63.

Suarez, I., Bodega, G., Rubio, N., and Fernandez, B. (1991). Sexual dimorphism in the distribution of glial fibrillary acidic protein in the supraoptic nucleus of tha hamster. J. Anat. 178, 79-82.

Tanapat, P., Hastings, N. B., Reeves, A. T., and Gould, E. (1999). Estrogen stimulates a transient increase in the number of new neurons in the dentate gyrus of the adult female rat. J. Neurosci. 19, 5792-5801.

Teixeira, C., Reed, J. C., and Pratt, M. A. C. (1995). Estrogen promotes chemotherapeutic drug resistance by a mechanism involv- ing $\mathrm{Bcl}$-2 proto-oncogene expression in human breast cancer cells. Cancer Res. 55, 3902-3907.

Tobet, S. A., and Fox, T. O. (1989). Sex- and hormone-dependent antigen immunoreactivity in developing rat hypothalamus. Proc. Natl. Acad. Sci. USA 86, 382-386.

Toran-Allerand, D. (1996). The estrogen-neurotrophin connection during neural develpment: Is co-localization of oestrogen receptor with neurotrophins and their receptors biologically relevant? Dev. Neurosci. 18, 36-42.

Uchibori, M., and Kawashimi, A. S. (1985). Effects of sex steroids on the growth of neuronal processes in neonatal rat hypothalamicpreoptic area and cerebral-cortex in primary culture. Int. J. Dev. Neurosci. 3, 169-174.

Van Itallie, C. M., and Dannies, P. (1988). Estrogen induces accumulation of the mitochondrial ribonucleic acid for subunit II of cytochrome oxidase in pituitary tumor cells. Mol. Endocrinol. 2, 332-337.

Vegeto, E., Pollio, G., and Maggi, A. (1999). Estrogen and progesterone induction of survival of monoblastoid cell undergoing TNF- $\alpha$-induced apoptosis. FASEB J. 13, 793-803.

Vegeto, E., Bonincontro, C., Pollio, G., Sala, A., Viappiani, S., Nardi, F., Puglisi, L., Ciana, P., and Maggi, A. (2000). Estrogen prevents the LPS-induced inflammatory response in microglia. J. Neurosci. 21, 1809-1818.

Verkhratsky, A., and Kettenmann, H. (1996). Calcium signalling in glial cells. Trends Neurosci. 19, 346-352.

Wersinger, S. R., Sannen, K., Villalba, C., Lubahn, D. B., Rissman, E. F., and De Vries, G. S. (1997). Masculine sexual behavior is disrupted in male and female mice lacking a functional estrogen receptor alpha gene. Horm. Behav. 32, 176-183.

Wolley, C. S., and McEwen, B. S. (1992). Estradiol mediates fluctuation in hippocampal synapse density during the estrous cycle in the adult brain. J. Neurosci. 12, 2549-2554.

Xu, H., Gouras, G. K., Greenfield, J. P., Vincent, B., Naslund, J., Mazzarelli, L., Fried, G., Jovanovic, J. N., Seeger, M., Relkin, N. R., Liao, F., Checler, F., Buxbaum, J. D., Thinakaran, G., Sisodia, S. S., Wang, R., Greengard, P., and Gandy, S. (1998). Nature Med. 4, 447-451. 